\title{
In memoriam Rodolphe Meyer
}

Tod eines Pioniers der Plastischen Chirurgie

Dr. med. Rodolphe Meyer ist tot. Er hat uns im Alter von 94 Jahren verlassen.

Geboren 1918 im Tessin, absolvierte er das Medizinstudium in Basel. Bald zog es ihn zu den Koryphäen der damaligen Zeit: nach England, Frankreich und den USA. Sein Hauptinteresse galt schon früh der Nase, was sich in zahlreichen Vorträgen, über 400 Publikationen und Büchern widerspiegelt.

Als Privatdozent der Universität Lausanne und Chefarzt der Plastischen Chirurgie schuf er die erste Weiterbildungsstätte für Plastische Chirurgie. Er erkannte schon früh die Bedeutung des Faches und gründete mit 11 weiteren Kollegen 1964 die Schweizerische Gesellschaft für Plastische Chirurgie, deren Präsident er 1967 war. Selbstredend gehörte er auch zu den Gründungsmitgliedern der ISAPS (International Society of Aesthetic Plastic Surgery). 1972 eröffnete er mit Kollegen ein privates Zentrum für Plastische Chirurgie in Lausanne.

Rodolphe Meyer war ein geschätzter, kompetenter Wissenschafter und witziger Redner. Als Ehrenmitglied nahm er bis zuletzt an den Jahrestagungen der Gesellschaft aktiv teil, zuletzt am ISAPS-Kongress in Genf 2012. Schade, dass er nächstes Jahr nicht mehr dabei sein darf. Die Gesellschaft feiert nämlich ihr 50-jähriges Bestehen.

Die Malerei war seine zweite Leidenschaft. Spon$\tan$ ersetzte er die Fotografie des Kongresszentrums Bocken, die sich auf dem Vorprogramm der 47. Jahrestagung befand, durch ein prachtvolles Ölgemälde (s. Abbildung), das er dann der damaligen Präsidentin Prof. Claudia Meuli-Simmen schenkte.

Mit dem Hinschied von Rodolphe Meyer verliert die Schweizerische Gesellschaft für Plastische, Rekonstruktive und Ästhetische Chirurgie einen Vorreiter des Faches, einen Freund sowie ein Vorbild.

Sein Gedächtnis wird u.a. dank seiner wissenschaftlichen Bibliothek, die er dem CHUV vermachte, erhalten bleiben. Diese Bibliothek zeichnet die Grundlagen der universitären Plastischen Chirurgie in der Schweiz auf, die Entwicklung der Rhinoplastik sowie weitere der Plastischen Chirurgie inhärente Techniken.

Für die Schweizerische Gesellschaft für Plastische, Rekonstruktive und Ästhetische Chirurgie:

Dr. med. Jean-François Emeri (Präsident 2008-2010),

Prof. Dr. med. Claudia Meuli-Simmen (Präsidentin 2010-2012),

Prof. Dr. med. Brigitte Pittet-Cuénod (Präsidentin)

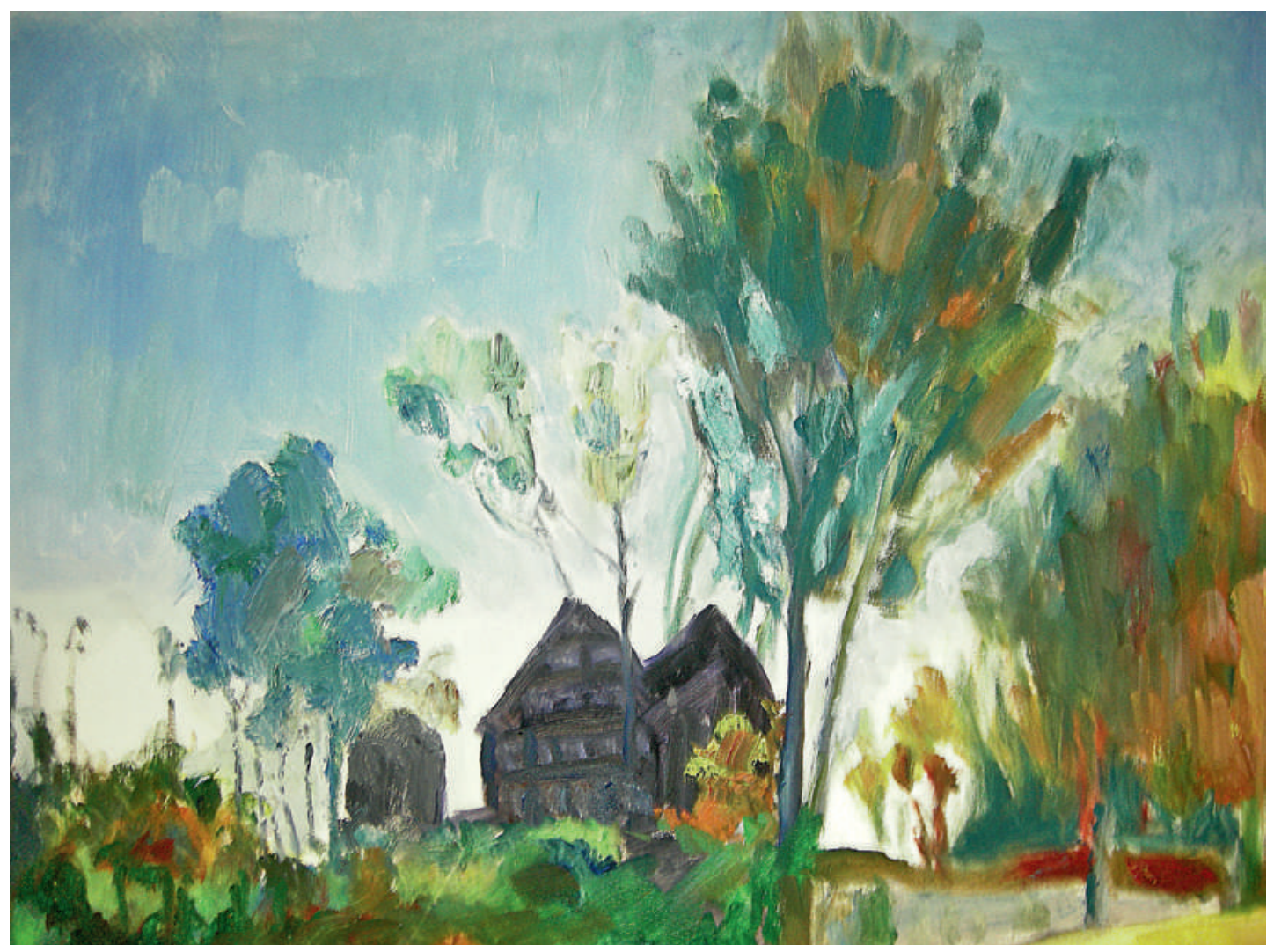

